\title{
Evidence of pulmonary vascular disease after heart transplantation for Fontan circulation failure
}

\author{
Max B. Mitchell, MD \\ David N. Campbell, MDa \\ Dunbar Ivy, $\mathrm{MD}^{\mathrm{b}}$ \\ Mark M. Boucek, MD \\ Henry M. Sondheimer, MD \\ Biagio Pietra, $M D^{b}$ \\ Bibhuti B. Das, MD \\ Joseph R. Coll, $\mathrm{PhD}^{\mathrm{b}}$
}

From the Departments of Surgery ${ }^{\mathrm{a}}$ and Pediatrics, ${ }^{\mathrm{b}}$ University of Colorado Health Sciences Center and the Children's Hospital, Denver, Colo.

Read at the Eighty-third Annual Meeting of The American Association for Thoracic Surgery, Boston, Mass, May 4-7, 2003.

Received for publication May 1, 2003; revisions received June 30, 2004; accepted for publication July 14, 2004.

Address for reprints: Max B. Mitchell, MD, The Children's Hospital, 1056 E 19th Ave, B200, Denver, CO 80218 (Email: mitchell.max@tchden.org).

J Thorac Cardiovasc Surg 2004;128: 693-702

$0022-5223 / \$ 30.00$

Copyright $\odot 2004$ by The American Association for Thoracic Surgery

doi:10.1016/j.jtcvs.2004.07.013
Objectives: Elevated pulmonary vascular resistance may contribute to late Fontan circulation failure but is difficult to assess in such patients. Our aims were to assess outcomes of patients with failed Fontan circulation after heart transplantation and to determine whether elevated pulmonary vascular resistance might have contributed to the failure.

Methods: Fifteen patients (14 Fontan circulations, 1 Kawashima circulation) underwent transplantation. The most common indication was ventricular dysfunction (mean ventricular end-diastolic pressure $12.5 \mathrm{~mm} \mathrm{Hg}$ ). Patients with early failures $(\mathrm{n}=4)$ required transplantation less than 1 year after the Fontan operation. Those with late failures $(\mathrm{n}=11)$ underwent transplantation at least 1 year after the Fontan operation. Mean age at transplantation was 11.6 years. Mean Fontan-transplantation interval was 7.4 years. Mean pulmonary arterial pressure, transpulmonary gradient, and pulmonary vascular resistance before and after transplantation were assessed. Paired $t$ tests of variable differences were used to compare variables. Survival was estimated by the Kaplan-Meier method.

Results: In-hospital mortality was 7\%. There were 2 late events (1 death, 1 retransplantation) related to compliance or rejection issues. Graft survivals were $93 \%, 82 \%$, and $82 \%$ at 3,5 , and 7 years, respectively. Posttransplantation pulmonary vascular resistance was elevated $\left(>2.0\right.$ Wood units $\left.\cdot \mathrm{m}^{2}\right)$ in 11 of 14 survivors past initial hospitalization (mean $3.3 \pm 1.7$ Wood units $\cdot \mathrm{m}^{2}$ ). Only patients with early Fontan failures ( 3 of 4 ) had normal posttransplantation pulmonary vascular resistance. In paired comparisons, posttransplantation transpulmonary gradient was increased by a mean of $6.8 \mathrm{~mm} \mathrm{Hg}(P<.0001)$ relative to pretransplantation value.

Conclusions: Outcomes after heart transplantation for failed Fontan circulation were good. Mild-to-moderate pulmonary vascular disease was evident after heart transplantation for late failure. Elevated pulmonary vascular resistance is a likely contributor to Fontan circulation failure.

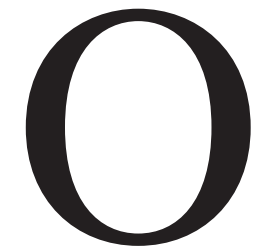

utcomes for recent modifications of the Fontan operation have shown significant improvement ${ }^{1-3}$; however, the durability of the palliated single-ventricle circulation remains limited. ${ }^{1,4-6}$ Mechanisms that contribute to late Fontan circulation attrition include loss of sinus rhythm, atrial tachyarrhythmia, suboptimal flow dynamics, pulmonary venous compression, atrioventricular valve regurgitation, subaortic obstruction, and progressive ventricular failure. ${ }^{7-9}$ Pulmo- 
TABLE 1. Patient diagnoses and palliation

\begin{tabular}{|c|c|c|c|c|}
\hline Patient & Diagnosis & Surgical history & $\begin{array}{l}\text { Fontan } \\
\text { age (y) }\end{array}$ & $\begin{array}{c}\text { Failure } \\
\text { interval }(y)^{*}\end{array}$ \\
\hline \multicolumn{5}{|l|}{ Early Fontan failures } \\
\hline 1 & TA, PA, Bilateral SVC & $\begin{array}{l}\text { MBT; bilateral BCPS; EC-F, coronary } \\
\text { artery bypass graft, left ventricular } \\
\text { assist device }\end{array}$ & 3.8 & 0.025 \\
\hline 2 & $\begin{array}{l}\text { Asplenia, situs inversus, TA, PS, bilateral } \\
\text { SVC }\end{array}$ & MBT; bilateral BCPS; EC-F & 3.4 & 0.38 \\
\hline 3 & Double-inlet left ventricle & $\begin{array}{l}\text { PAB; BCPS, pulmonary artery ligation, } \\
\text { EC-F }\end{array}$ & 4 & 0.39 \\
\hline 4 & Double-outlet right ventricle, MA, VSD & PAB; LT-F & 2.6 & 0.68 \\
\hline Mean \pm SD & & & $3.4 \pm 0.6$ & $0.37 \pm 0.27$ \\
\hline \multicolumn{5}{|l|}{ Late Fontan failures } \\
\hline 1 & $\begin{array}{l}\text { Polysplenia, unbalanced atrioventricular } \\
\text { septal defect, PA, interrupted inferior } \\
\text { vena cava with hemiazygous } \\
\text { continuation, bilateral SVC }\end{array}$ & MBT $\times 2$; Kawashima & 3.3 & 4.2 \\
\hline 2 & Single ventricle, PA, dextrocardia & MBT; CAPS; AP-F & 3.8 & 4.2 \\
\hline 3 & TA, PA & MBT; LT-F & 2 & 6.1 \\
\hline 4 & TA, PA & $\begin{array}{l}\text { WAPS; CAPS; MBT; AP-F; BCPS; } \\
\text { revised AP-F }\end{array}$ & 6.5 & 7.2 \\
\hline 5 & MA, PS, D-TGA, VSD & MBT, LT-F, revised LT-F & 4 & 8.2 \\
\hline 6 & PA-IVS & $\begin{array}{l}\text { CBT, classic cavopulmonary shunt, } \\
\text { AP-F }\end{array}$ & 1.3 & 8.3 \\
\hline 7 & TA, VSD, PS & WAPS; LT-F & 14.7 & 10.6 \\
\hline 8 & TA, VSD, PS & CBT; RARV-F; revised RARV-F & 6.7 & 10.9 \\
\hline 9 & $\begin{array}{l}\text { Polysplenia, MA, VSD, D-TGA, bilateral } \\
\quad \text { SVC }\end{array}$ & PAB; AP-F & 1.9 & 11.6 \\
\hline 10 & TA, VSD & PAB; RARV-F; revised RARV-F & 3.5 & 17.2 \\
\hline 11 & PA-IVS & $\begin{array}{l}\text { Formalinization of patent ductus } \\
\text { arteriosus; MBT } \times 2 \text {; AP-F; BCPS, } \\
\text { EC-F }\end{array}$ & 2.6 & 21.1 \\
\hline Mean $\pm S D$ & & & $4.6 \pm 3.8$ & $10.0 \pm 5.2$ \\
\hline Total mean $\pm S D(n=15)$ & & & $4.3 \pm 3.2$ & $7.4 \pm 6.2$ \\
\hline
\end{tabular}

Semicolons delineate separate surgical procedures. TA, Tricuspid atresia; $P A$, pulmonary atresia; $S V C$, superior vena cava; $M B T$, modified Blalock-Taussig shunt; $B C P S$, bidirectional cavopulmonary shunt; $E C-F$, extracardiac conduit Fontan; $P S$, pulmonary stenosis; $P A B$, pulmonary artery banding; $M A$, mitral atresia; VSD, ventricular septal defect; $L T-F$, lateral tunnel Fontan; CAPS, central aortopulmonary shunt; $A P-F$, atriopulmonary Fontan; WAPS, Waterston aortopulmonary shunt; $D-T G A$, dextrotransposition of the great arteries; $P A$-IVS, pulmonary atresia with intact ventricular septum; $C B T$, classic BlalockTaussig shunt; RARV-F, right atrial-right ventricle Fontan connection.

* Measured from date of first Fontan operation to transplantation.

nary vascular disease clearly increases Fontan operative risk and the risk of early failure. ${ }^{10}$ In contrast, the impact of the pulmonary vascular bed on medium- and long-term outcomes after Fontan surgery has not been defined. It is possible that the Fontan state itself may induce the development or progression of pulmonary vascular disease, thus negatively influencing long-term outcome. ${ }^{5}$ Low cardiac output, multiple sources of pulmonary blood flow, presence of pulmonary arteriovenous malformations (PAVMs), and other unique factors limit the accuracy of pulmonary vascular resistance (PVR) determination in patients with failing Fontan circulations. ${ }^{11}$ Consequently, it is difficult to quantify pulmonary vascular disease in such patients, and the influence of pulmonary vascular disease on late Fontan circulation failure is unknown.

Heart transplantation is the only option after failed single-ventricle palliation, provided that failure is not due to correctable flow dynamics or arrhythmias. There have been few studies reporting outcomes in patients undergoing transplantation after a Fontan operation. ${ }^{11-15}$ Small patient numbers, limited follow-up, and substantial surgical mortality characterize these reports. Because right ventriclepulmonary artery coupling is inherently absent in the Fontan circulation, it is tempting to assume that PVR in the patient with failing Fontan circulation must fall within safely transplantable limits. However, these reports indicate a substan- 
TABLE 2. Transplantation indications and outcomes

\begin{tabular}{|c|c|c|c|c|c|c|}
\hline Patient & Transplant indications & $\begin{array}{l}\text { UNOS } \\
\text { status }\end{array}$ & $\begin{array}{l}\text { VEDP* } \\
(\mathrm{mm} \mathrm{Hg})\end{array}$ & $\begin{array}{c}\text { Transplant } \\
\text { age }(y)\end{array}$ & $\begin{array}{l}\text { Follow-up } \\
\quad \text { (y) }\end{array}$ & Status \\
\hline \multicolumn{7}{|c|}{ Early Fontan failures } \\
\hline 1 & $\begin{array}{l}\text { Ventricular failure (left coronary artery injury } \\
\text { at extracardiac conduit Fontan, left } \\
\text { ventricular assist device) }\end{array}$ & $1 \mathrm{a}$ & ND & 3.8 & 3.2 & Alive \\
\hline 2 & $\begin{array}{l}\text { Ventricular dysfunction, atrioventricular } \\
\text { valve regurgitation }\end{array}$ & $1 \mathrm{a}$ & 15 & 3.8 & 3.6 & Alive \\
\hline 3 & Ventricular dysfunction & 1a & 16 & 4.4 & 3.4 & Alive \\
\hline 4 & Ventricular dysfunction & $1 \mathrm{a}$ & 9 & 3.3 & 6.5 & Alive \\
\hline Mear & & & $13.3 \pm 3.8$ & $3.8 \pm 0.5$ & $4.1 \pm 1.6$ & \\
\hline \multicolumn{7}{|c|}{ Late Fontan failures } \\
\hline $1 \dagger$ & Ventricular dysfunction, cyanosis, PAVMs & $1 b$ & 14 & 7.5 & 9.2 & Alive \\
\hline 2 & PLE & $1 b$ & 9 & 8.0 & 8.2 & Alive \\
\hline 3 & $\begin{array}{l}\text { Ventricular dysfunction, right pulmonary vein } \\
\text { obstruction }\end{array}$ & 2 & 10 & 8.1 & 7.8 & Dead \\
\hline 4 & $\begin{array}{l}\text { Ventricular dysfunction, functional single } \\
\text { lung }\end{array}$ & $1 b$ & ND & 13.8 & 4.5 & $\operatorname{ReTx}$ \\
\hline 5 & PLE, atrial flutter & $1 b$ & 8 & 12.1 & 4.2 & Alive \\
\hline 6 & $\begin{array}{l}\text { Ventricular dysfunction, cardiogenic } \\
\text { cirrhosis }\end{array}$ & $1 \mathrm{~b}$ & 7 & 9.7 & 11.1 & Alive \\
\hline 7 & Ventricular dysfunction & 2 & 12 & 25.2 & 12.8 & Alive \\
\hline 8 & Ventricular dysfunction, PLE, atrial flutter & 2 & 16 & 17.6 & 0.5 & Dead $\neq$ \\
\hline 9 & Ventricular dysfunction, PLE, atrial flutter & $1 b$ & 12 & 13.5 & 7.8 & Alive \\
\hline 10 & Ventricular dysfunction & $1 \mathrm{a}$ & 12 & 20.6 & 3.2 & Alive \\
\hline 11 & Ventricular dysfunction, PAVMs, atrial flutter & $1 b$ & 18 & 23.6 & 2.3 & Alive \\
\hline \multicolumn{2}{|c|}{ Mean \pm SD } & & $11.8 \pm 3.5$ & $14.5 \pm 6.4$ & $6.5 \pm 3.9$ & \\
\hline \multicolumn{3}{|c|}{ Total mean $\pm S D(n=15)$} & $12.5 \pm 7.8$ & $11.6 \pm 7.3$ & $5.9 \pm 3.5$ & \\
\hline
\end{tabular}

UNOS, United Network for Organ Sharing; VEDP, ventricular end-diastolic pressure; ND, not determined; ReTx, repeat transplantation.

*Pretransplantation catheterization.

tKawashima.

‡ln-hospital death.

tial incidence of right ventricular failure after transplantation, suggesting that PVR may be elevated in some patients.

In this study we postulated that patients with failed Fontan circulations who underwent conversion to biventricular physiology with heart transplantation would provide an ideal cohort to investigate whether pulmonary vascular disease is present in patients with failing single-ventricle circulation. The specific aims of this report were as follows: to assess the outcomes of patients undergoing heart transplantation in our center for failing Fontan circulations and to determine whether pulmonary vascular disease was present in these patients.

\section{Patients and Methods}

\section{Patient Population}

All patients who underwent transplantation in our center through December 31, 2002, for failing Fontan and Kawashima circulations were identified. Medical records were examined retrospectively, and a separate research database was compiled, eliminating all identifying information. The Colorado Multiple Institution Review Board approved this study. Fifteen patients (14 Fontan circulations, 1 Kawashima circulation) underwent transplantation.
There were no deaths among similar patients on the waiting list. Table 1 lists diagnoses and surgical summaries of transplant recipients. Ventricular dominance was left in 10 patients and right in 5. Fontan modifications at transplantation included 5 lateral tunnels, 4 extracardiac conduits, 3 atriopulmonary connections, and 2 right atrial-right ventricular conduits ( $\mathrm{n}=14$ total). Fontan pathway fenestration was performed in only 1 patient, and the fenestration closed spontaneously before pretransplantation assessment. The mean number of previous cardiac procedures was $3.5 \pm 1.5$.

Table 1 segregates patients by time to palliation failure (early $<1$ year vs late $\geq 1$ year). Transplantation indications, United Network for Organ Sharing status at the time of transplantation, and outcomes are given in Table 2. Ventricular dysfunction was the most common indication. Pretransplantation ventricular enddiastolic pressure was elevated ( $\geq 12 \mathrm{~mm} \mathrm{Hg}$ ) in 8 of 13 patients in whom it was measured. One patient with late Fontan circulation failure had protein-losing enteropathy (PLE) only. Three patients with late Fontan circulation failure had both PLE and intermittent atrial flutter. A fourth patient with late Fontan circulation failure had both atrial flutter and PAVMs. No other patients had known atrial tachyarrhythmia. PAVMs were documented in the patient with Kawashima circulation failure. 


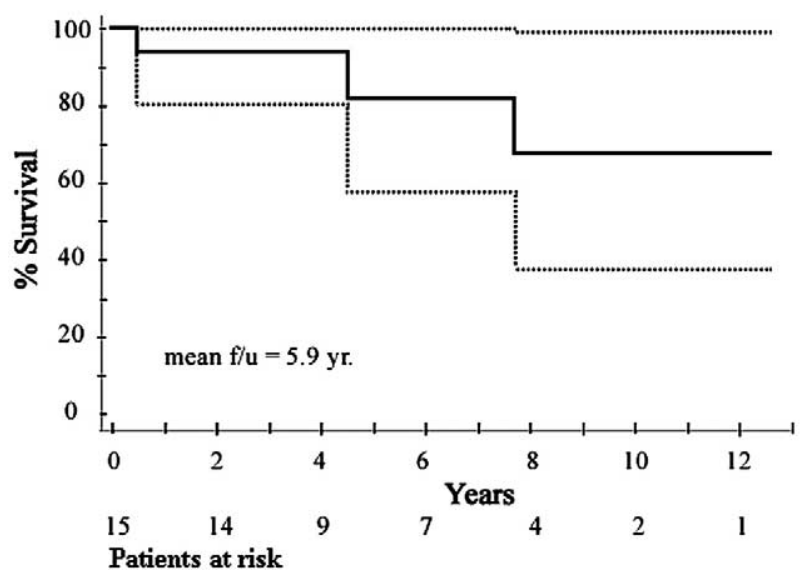

Figure 1. Kaplan-Meier-estimated survival of all patients. Dashed lines indicate $95 \%$ confidence limits. $f / u$, Follow-up.

\section{Transplantation Management}

All recipients were matched with $\mathrm{ABO}$-compatible donors. Donor hearts were preserved with $4^{\circ} \mathrm{C}$ Roe solution, and additional donor tissue was procured whenever possible to facilitate systemic venous and pulmonary artery reconstruction at transplantation. Aprotinin was used routinely. Posttransplantation management and immune suppression were as previously reported by our institution. ${ }^{16}$ The posttransplantation rejection surveillance protocol in our center is as follows. Heart catheterization with endomyocardial biopsy and coronary artery assessment is performed for rejection surveillance within 12 months of transplantation. Patients with acute rejection episodes more than 3 months after transplantation undergo surveillance catheterization at 3 to 6 months after the rejection episode. Coronary angiography and intravascular ultrasound are used to screen for graft coronary artery disease (CAD).

\section{Pulmonary Hemodynamics}

Variables of pulmonary vascular status considered were mean pulmonary artery pressure (PAP), transpulmonary gradient (TPG), and PVR. Available data were collected from catheterizations before and after transplantation. In 2 patients branch pulmonary artery stenoses were corrected with balloon angioplasty before pretransplantation hemodynamic evaluation. No other patients had branch pulmonary stenosis identified at pretransplantation evaluation. Posttransplantation comparisons of variables were determined from data obtained at the time of first routine surveillance catheterization. Catheterizations performed for suspected rejection and studies demonstrating active rejection were excluded. All catheterizations were performed with local anesthesia, conscious sedation as required, and spontaneous ventilation (arterial $\mathrm{PCO}_{2}$ range $35-45 \mathrm{~mm} \mathrm{Hg}$ ) on room air. Because the pretransplantation measurement of pulmonary blood flow is subject to significant error in the patient population under study, PVR was not routinely assessed during pretransplantation evaluation. The primary factor considered in the pretransplantation assessment of pulmonary vascular disease was TPG. All surviving patients had PVR measured at posttransplantation assessment. Previously published normal values were used for the assessment of pulmonary hemodynamics. $^{17,18}$

\section{Definitions and Statistical Analysis}

In-hospital mortality was defined as death before discharge from the hospital after transplantation. Intensive care and hospital stays were determined from the time of transplantation. Pretransplantation versus posttransplantation mean PAP, TPG, and PVR values were compared with paired $t$ tests of mean differences to test the null hypothesis that the difference was zero. Paired comparisons were made for the entire patient population, and patients with late Fontan circulation failure were also compared separately. For all comparisons, patients missing paired data points and those with split sources of pulmonary blood flow before transplantation were excluded. The mean follow-up was 5.9 years (range 0.5-12.8 years) and was complete. Graft survival was estimated by the Kaplan-Meier method.

\section{Results}

\section{Transplant Procedures}

Median waiting list time was 28 days (range 2-669 days). The mean total graft ischemia time was $248 \pm 68$ minutes, and mean cardiopulmonary bypass time was $169 \pm 56$ minutes. Bicaval anastomotic techniques were used in 14 cases, and bilateral superior vena cava connections were necessary in 3 cases.

\section{Transplantation Hospital Course}

Complications occurred in 8 patients and were multiple in 6 cases. Complications resulted in major morbidity in 6 cases. Median posttransplantation intensive care and hospital stays were 8 days (range 3-148 days ) and 17 days (range 5-179 days). One in-hospital death (7\%) occurred in a patient with late Fontan circulation failure who had hepatic failure develop and underwent liver transplantation on postoperative day 30. This patient died of multiple organ failure on post-heart transplantation day 179. Pathologic evaluation of the explanted liver indicated occult cardiogenic cirrhosis.

\section{Late Outcomes}

Two late graft failures occurred, at 4.5 years (resulting in retransplantation) and 7.8 years (resulting in death). Estimated graft survivals at 3, 5, and 7 years were $93 \%, 82 \%$, and $82 \%$ (Figure 1). Both late graft failures were rejection related, and adolescent noncompliance was a major factor in each. Pathologic assessments revealed severe graft CAD in 1 case and moderate graft CAD in the other. Both cases evidenced myocardial injury from chronic rejection and severe acute rejection.

All 12 surviving patients were in New York Heart Association functional class I at most recent follow-up examination. Surveillance coronary evaluations revealed no evidence of graft CAD in 10 patients at a mean time from transplantation of $3.4 \pm 2.2$ years. Mild CAD was present in 2 patients on studies performed 5.7 and 6.6 years posttransplantation. One patient was successfully treated for posttransplantation lymphoproliferative disease. One patient (patient 2 in the early Fontan group) required reoperation at 
TABLE 3. Pretransplantation and posttransplantation pulmonary hemodynamics

\begin{tabular}{|c|c|c|c|c|c|c|}
\hline & \multicolumn{2}{|c|}{ Early Fontan } & \multicolumn{2}{|c|}{ Late Fontan } & \multicolumn{2}{|c|}{ All patients } \\
\hline & $\mathbf{n}$ & Mean \pm SD & $\mathrm{n}$ & Mean \pm SD & n & Mean \pm SD \\
\hline \multicolumn{7}{|l|}{ Mean PAP (mm Hg) } \\
\hline Pretransplantation & 4 & $17.0 \pm 5.0$ & 11 & $16.7 \pm 3.3$ & 15 & $16.8 \pm 3.6$ \\
\hline Posttransplantation & 4 & $17.8 \pm 4.0$ & 10 & $20.8 \pm 2.4$ & 14 & $19.9 \pm 3.3$ \\
\hline \multicolumn{7}{|l|}{ Mean TPG (mm Hg) } \\
\hline Pretransplantation & 4 & $6.0 \pm 2.0$ & 10 & $4.5 \pm 2.8$ & 14 & $4.9 \pm 2.8$ \\
\hline Posttransplantation & 4 & $10.5 \pm 1.7$ & 10 & $12.8 \pm 2.0$ & 14 & $12.1 \pm 1.4$ \\
\hline \multicolumn{7}{|c|}{ Mean PVR (Wood units $\cdot \mathrm{m}^{2}$ ) } \\
\hline Pretransplantation & 4 & $2.1 \pm 1.4$ & 5 & $1.5 \pm 0.7$ & 8 & $1.7 \pm 0.6$ \\
\hline Posttransplantation & 4 & $2.0 \pm 0.4$ & 10 & $3.8 \pm 0.8$ & 14 & $3.3 \pm 1.7$ \\
\hline
\end{tabular}

TABLE 4. Paired pretransplantation versus posttransplantation pulmonary hemodynamic comparisons

\begin{tabular}{|c|c|c|c|c|c|c|}
\hline \multirow[b]{2}{*}{ Variable } & \multirow[b]{2}{*}{$\mathbf{n}$} & \multirow[b]{2}{*}{ Before } & \multicolumn{3}{|c|}{ Mean } & \multirow[b]{2}{*}{$P$ value } \\
\hline & & & After & difference & SD & \\
\hline \multicolumn{7}{|l|}{ All patients } \\
\hline PAP (mm Hg) & 13 & $17.0 \pm 3.7$ & $19.7 \pm 3.3$ & 2.7 & 4.8 & .064 \\
\hline TPG (mm Hg) & 12 & $5.3 \pm 2.3$ & $12.0 \pm 2.1$ & 6.8 & 3.5 & $<.0001$ \\
\hline PVR (Wood units $\cdot \mathrm{m}^{2}$ ) & 6 & $1.8 \pm 1.1$ & $2.7 \pm 1.0$ & 0.8 & 1.7 & .296 \\
\hline \multicolumn{7}{|l|}{ Late Fontan failures } \\
\hline PAP (mm Hg) & 9 & $17.0 \pm 3.4$ & $20.6 \pm 2.5$ & 3.6 & 4.8 & .057 \\
\hline TPG (mm Hg) & 8 & $4.9 \pm 2.5$ & $12.8 \pm 2.0$ & 7.9 & 3.6 & .0004 \\
\hline PVR (Wood units $\cdot \mathrm{m}^{2}$ ) & 3 & $1.5 \pm 0.9$ & $3.5 \pm 0.7$ & 2.0 & 1.5 & .155 \\
\hline
\end{tabular}

Comparisons made with $t$ test of the difference in paired data, testing the null hypothesis that the difference in mean values was 0 . Patient 6 in late Fontan failure group was excluded from comparisons because of split pulmonary artery circulation before transplantation (classic cavopulmonary shunt with right pulmonary artery and atriopulmonary Fontan with left pulmonary artery).

15 months for pulmonary venous obstruction. This patient had situs inversus with bilateral superior caval veins and underwent transplantation with the method previously reported by Vricella and associates. ${ }^{19}$ At reoperation, stricture of the left atrial anastomosis was identified and corrected with a "sutureless" pericardial augmentation. All surviving patients with PAVMs $(\mathrm{n}=2)$ and PLE $(\mathrm{n}=3)$ had resolution within 6 months of transplantation.

\section{Pulmonary Hemodynamics}

Pulmonary hemodynamic evaluations are summarized in Table 3. Posttransplantation mean PAP was elevated $(>18$ $\mathrm{mm} \mathrm{Hg}$ ) in 8 patients. Seven of 10 surviving patients with late Fontan circulation failure had elevated mean PAP (range 19-24 $\mathrm{mm} \mathrm{Hg}$ ), and the 3 patients in this group with normal mean PAP were all at the upper limit of normal (18 $\mathrm{mm} \mathrm{Hg}$ ). In contrast, only 1 of the 4 patients with early Fontan circulation failure had elevated mean PAP after transplantation. Posttransplantation TPG was elevated ( $>9$ $\mathrm{mm} \mathrm{Hg}$ ) in 13 patients. All patients with late Fontan circulation failure had elevated posttransplantation TPG (range 10-16 mm Hg). Posttransplantation PVR was elevated in all
10 surviving patients with late Fontan circulation failure (range 2.8-5.4 Wood units $\cdot \mathrm{m}^{2}$ ). Posttransplantation PVR was mildly elevated in only 1 of the 4 patients with early Fontan circulation failure. These data indicate that patients with late-failing Fontan circulations had a high prevalence of underlying mild-to-moderate pulmonary vascular disease.

Table 4 presents paired pretransplantation versus posttransplantation comparisons (includes only patients with variables measured at pretransplantation and posttransplantation catheterization). When all patients with paired data were considered, TPG increased by a mean of $6.8 \mathrm{~mm} \mathrm{Hg}$ after transplantation $(P<.001)$. Mean PAP averaged 2.7 $\mathrm{mm} \mathrm{Hg}$ higher after transplantation, but this increase was of marginal significance $(P=.064)$. Findings were similar when the late Fontan group was analyzed separately, with a marginally significant increase in mean PAP $(3.6 \mathrm{~mm} \mathrm{Hg}, P$ $=.057)$ and an increase in TPG of $7.9 \mathrm{~mm} \mathrm{Hg}(P=.0004)$. Our institutional bias is that pulmonary blood flow cannot be accurately measured in the failing Fontan state. ${ }^{11}$ PVR was not measured during the pretransplantation evaluation 
in 7 patients. Consequently, paired pretransplantation and posttransplantation PVR data were limited, and no differences were identified for the entire population or the late Fontan failure group. However, TPGs that increased to pathologic levels after transplantation are consistent with the restoration of normal pulmonary blood flow in the presence of mild-to-moderate pulmonary vascular disease. Thus, our data indicate that "normal" pulmonary hemodynamic values measured in the failing Fontan circulation do not necessarily exclude the presence of pulmonary vascular disease.

\section{Discussion}

Our findings indicate that heart transplantation is effective therapy with good early and medium-term outcomes for patients with failing Fontan circulations. These results also provide clinical evidence that patients with late-failing Fontan circulations had a high incidence of mild-to-moderate pulmonary vascular disease. It is therefore likely that pulmonary vascular disease contributed to Fontan failure in these patients.

We agree with Carey and colleagues ${ }^{11}$ that measurements of pulmonary blood flow in the patient with a failing Fontan circulation are unreliable and that the calculation of a normal PVR in these patients does not exclude pulmonary vascular disease. The elevated TPGs observed at posttransplantation evaluation indicate that one also cannot use normal values of this parameter in the pretransplantation assessment of pulmonary hemodynamics without significantly underestimating pulmonary vascular disease in these patients. The posttransplantation increase in TPG is explained by the low cardiac output and limited pulmonary blood flow present before transplantation in the failing patient. After transplantation, the increase in TPG to pathologic levels reflects a fixed element of PVR that was unmasked with the introduction of normal pulmonary blood flow. Only one patient in this series had acute graft failure (Tables 1 and 2, patient 10 of the late Fontan group), primarily as a result of cold injury. The donor heart was packed with excessive ice, and the infundibular free wall of the right ventricle was frozen solid. This patient survived with a short period of biventricular assistance. The magnitude of pulmonary vascular disease was therefore not sufficient to precipitate lethal acute graft failure in these patients.

Even modest increases in PVR are likely to have a negative impact on Fontan circulation longevity, because the Fontan pathway places the pulmonary capillary bed in series with the systemic and splanchnic capillary beds. ${ }^{5,20}$ This study suggests but does not verify a causal relationship between the long-term presence of the Fontan circulation and the development or progression of pulmonary vascular disease. Serial assessments of PVR during the Fontan state would be necessary to demonstrate that the Fontan circula- tion itself promotes increased PVR. However, as noted previously, we and others do not believe that PVR can be reliably measured in the failing Fontan circulation, ${ }^{11}$ and proof that the Fontan circulation promotes increased PVR is therefore elusive.

Other factors may explain the presence of pulmonary vascular disease in our group with late Fontan circulation failure. Two early patients with Fontan circulation failure underwent systemic-pulmonary shunts for durations of 6 and 12 months before bidirectional cavopulmonary shunt procedures, whereas 8 of the 11 patients with late failure of Fontan circulation underwent one or more palliative systemic-pulmonary shunt procedures that were in place for durations ranging from 6 months to 124 months. In addition, no patient in the late Fontan failure group underwent a bidirectional superior cavopulmonary shunt before the Fon$\tan$ operation, whereas 3 of 4 patients with early Fontan circulation failure underwent bidirectional superior cavopulmonary shunt before the Fontan operation. Thus, inadequate protection of the pulmonary vasculature before the Fontan operation could account for the abnormal PVR observed after transplantation in the late Fontan failure group. However, the fact that the late failure Fontan group demonstrated reasonable palliation for several years before transplantation (range 4.2-21.1 years) suggests that significant pulmonary vascular disease was not present before Fontan palliation in this group. It is also possible that transplantation or immunosuppressive medications required after transplantation might account for our findings, but the lower posttransplantation PAP and TPG and the normal PVR observed after transplantation in the early Fontan failure group argue against this explanation.

There are several mechanisms by which the Fontan circulation may increase PVR. Many investigators have reported catastrophic thromboembolic events in patients with Fontan circulations. ${ }^{21}$ Less evident chronic microemboli could lead to progressive development of increased PVR. In the normal circulation, a significant portion of the energy transmitted to the pulmonary artery by right ventricular ejection is required to maintain patency of the distal pulmonary vascular bed. ${ }^{5,22}$ de Leval ${ }^{5}$ has proposed that the lower-energy pulmonary circulation inherent in the Fontan circuit effectively increases pulmonary vascular impedance, therefore increasing PVR. Elevated pulmonary lymphatic pressure from transmission of increased central venous pressure in the Fontan state could also increase PVR because of pulmonary edema. ${ }^{5}$

Congenital heart disease remains the most powerful risk factor for death within 1 year of transplantation in the pediatric age group. ${ }^{23}$ Patients with previous Fontan operations represent one of the most challenging subgroups requiring transplantation. Our results compare favorably with other series (mortality range 14\%-66\%). ${ }^{11-15}$ Hemor- 
rhage and donor graft failure were the primary causes of early mortality in these reports. Pulmonary vascular disease may have contributed to early deaths reported by other centers. Lengthy cardiopulmonary bypass times and large transfusion requirements typical with such patients may have acutely potentiated significant underlying pulmonary vascular disease, resulting in acute graft failure. For this reason we recommend avoidance of undersized and marginal donors in these cases.

Medium-term survival in our series was relatively good. Unfortunately, noncompliance with immunosuppression had a significant impact on late outcomes in our adolescent patients, and graft rejection will doubtless lead to continued attrition. Consequently, heart transplantation should be the treatment of last resort in patients with failing Fontan circulations. Patients with hemodynamically suboptimal Fontan connections should undergo Fontan revision, provided that ventricular dysfunction can be attributed to correctable anatomic or rhythm-related issues. $^{24-26}$ Mavroudis and colleagues ${ }^{26}$ have demonstrated superb results for Fontan revision combined with antiarrhythmia surgery in patients with atrial tachyarrhythmias. However, their series included no patients with PLE. These authors have also suggested that patients with significant ventricular dysfunction evidenced by a ventricular end-diastolic pressure greater than $12 \mathrm{~mm} \mathrm{Hg}$ are at increased risk for combined Fontan conversion and maze procedure. In our series there were 4 patients with known atrial tachyarrhythmias (Table patients 2, 5, 8, 9, and 11 in the late failure group). Three of these patients also had PLE. The fourth patient had persisting severe PAVMs after narrowly surviving conversion to a total cavopulmonary connection (without antiarrhythmia surgery) at another institution 1 year before transplantation. Patient 8 in the late failure group (Tables 1 and 2) had PLE and was the only in-hospital death in our series. The other 3 patients with atrial arrhythmias had resolution of PLE and PAVMs after transplantation. In our view, patients with significant ventricular dysfunction (ventricular end-diastolic pressure $>12 \mathrm{~mm}$ $\mathrm{Hg}$ ) and patients with PLE are at high risk when undergoing Fontan revision with or without antiarrhythmia surgery and are probably better served by transplantation. ${ }^{15,26}$

In summary, this study demonstrates that heart transplantation is effective treatment for patients with end-stage heart disease with failed Fontan circulations. Morbidity in this patient population is considerable, but good early and medium-term outcomes can be achieved in this challenging subgroup of patients with congenital heart disease. As with all patients requiring heart transplantation, long-term survival is limited by rejection. This study also demonstrates that underlying pulmonary vascular disease becomes apparent after heart transplantation in patients with late-failing Fontan circulations. Further study is required to delineate whether the Fontan circulation itself induces pulmonary vascular disease and to asses the impact this process may have on Fontan attrition.

\section{References}

1. Fontan F, Kirklin JW, Fernandez G, Costa F, Naftel DC, Tritto F, et al. Outcome after a "perfect" Fontan operation. Circulation. 1990;81: 1520-36.

2. Freedom RM, Hamilton R, Yoo SJ, Mikailian H, Benson L, McCrindle B, et al. The Fontan procedure: analysis of cohorts and late complications. Cardiol Young. 2000;10:307-31.

3. Stamm C, Friehs I, Mayer JE, Zurakowski D, Triedman JK, Moran AM, et al. Long-term results of the lateral tunnel Fontan operation. J Thorac Cardiovasc Surg. 2001;121:28-41.

4. Gentles TL, Mayer JE, Gauvreau K, Newburger JW, Lock JE, Kupferschmid JP, et al. Fontan operation in five hundred consecutive patients: factors influencing early and late outcome. J Thorac Cardiovasc Surg. 1997;114:376-91.

5. de Leval MR. The Fontan circulation: what have we learned? What to expect? Pediatr Cardiol. 1998;19:316-20.

6. Yeh T Jr, Williams WG, McCrindle BW, Benson LN, Coles JG, Van Arsdell GS, et al. Equivalent survival following cavopulmonary shunt: with or without the Fontan procedure. Eur J Cardiothorac Surg. 1999;16:111-6.

7. Scholl FG, Alejos JC, Laks H. Revision of the traditional atriopulmonary Fontan connection. Adv Card Surg. 1997;9:217-27.

8. Durongpisitkul K, Porter CJ, Cetta F, Offord KP, Slezak JM, Puga FJ, et al. Predictors of early- and late-onset supraventricular tachyarrhythmias after Fontan operation. Circulation. 1998;98:1099-107.

9. Piran S, Veldtman G, Siu S, Webb GD, Liu PP. Heart failure and ventricular dysfunction in patients with single or systemic right ventricles. Circulation. 2002;105:1189-94.

10. Yamaki S, Ajiki H, Haneda K, Takanashi Y, Ban T, Takahashi T. Pulmonary arterial changes in patients dying after a modified Fontan procedure following pulmonary artery banding. Heart Vessels. 1994; 9:263-8.

11. Carey JA, Hamilton JR, Hilton CJ, Dark JH, Forty J, Parry G, et al. Orthotopic cardiac transplantation for the failing Fontan circulation. Eur J Cardiothorac Surg. 1998;14:7-14.

12. Hsu DT, Quaegebeur JM, Michler RE, Smith CR, Rose EA, Kichuk $\mathrm{MR}$, et al. Heart transplantation in children with congenital heart disease. J Am Coll Cardiol. 1995;26:743-9.

13. Lamour JM, Addonizio LJ, Galantowicz ME, Quaegebeur JM, Mancini DM, Kichuk MR, et al. Outcome after orthotopic cardiac transplantation in adults with congenital heart disease. Circulation. 1999; 100(19 Suppl):II200-5.

14. Michielon G, Parisi F, Di Carlo D, Squitieri C, Carotti A, Buratta M, et al. Orthotopic heart transplantation for failing single ventricle physiology. Eur J Cardiothorac Surg. 2003;24:502-10.

15. Gamba A, Merlo M, Fiocchi R, Terzi A, Mammana C, Sebastiani R, et al. Heart transplantation in patients with previous Fontan operations. J Thorac Cardiovasc Surg. 2004;127:555-62.

16. Fullerton DA, Campbell DN, Jones SD, Jaggers J, Brown JM, Wollmering MM, et al. Heart transplantation in children and young adults: early and intermediate-term results. Ann Thorac Surg. 1995; 59:804-12.

17. Reeves JT, Groves BM. Approach to the patient with pulmonary hypertension. In: Weir KE, Reeves JT, editors. Pulmonary hypertension. Mount Kisco (NY): Futura; 1984. p. 2-5.

18. Vargo TA. Cardiac catheterization-hemodynamic measurements. In: Garson A Jr, Bricker TT, McNamara DG, editors. The science and practice of pediatric cardiology. Philadelphia: Lea \& Febiger; 1990. p. 932.

19. Vricella LA, Razzouk AJ, Gundry SR, Larsen RL, Kuhn MA, Bailey LL. Heart transplantation in infants and children with situs inversus. J Thorac Cardiovasc Surg. 1998;116:82-9.

20. Hsia TY, Khambadkone S, Redington AN, Migliavacca F, Deanfield JE, de Leval MR. Effects of respiration and gravity on infradiaphragmatic venous flow in normal and Fontan patients. Circulation. 2000; 102(19 Suppl 3):III148-53. 
21. Jahangiri M, Ross DB, Redington AN, Lincoln C, Shinebourne EA. Thromboembolism after the Fontan procedure and its modifications. Ann Thorac Surg. 1994;58:1409-14.

22. Milnor NR. Pulmonary hemodynamics. In: Bergel DH, editor. Cardiovascular fluid dynamics. London: Academic Press; 1972.

23. Boucek MM, Edwards LB, Keck BM, Trulock EP, Taylor DO, Mohacsi PJ, et al. The Registry of the International Society for Heart and Lung Transplantation: Fifth Official Pediatric Report-2001 to 2002. J Heart Lung Transplant. 2002;21:827-40.

24. McElhinney DB, Reddy VM, Moore P, Hanley FL. Revision of previous Fontan connections to extracardiac or intraatrial conduit cavopulmonary anastomosis. Ann Thorac Surg. 1996;62:1276-83.

25. Marcelletti CF, Hanley FL, Mavroudis C, McElhinney DB, Abella RF, Marianeschi SM, et al. Revision of previous Fontan connections to total extracardiac cavopulmonary anastomosis: a multicenter experience. J Thorac Cardiovasc Surg. 2000;119:340-6.

26. Mavroudis C, Backer CL, Deal BJ, Johnsrude C, Strasburger J. Total cavopulmonary conversion and maze procedure for patients with failure of the Fontan operation. J Thorac Cardiovasc Surg. 2001;122:863-71.

\section{Discussion}

Dr Carl L. Backer (Chicago, Ill). I congratulate Mitchell and coworkers from Denver on their outstanding results with heart transplantation in patients with a failed Fontan circulation. These patients have usually had at least two or three previous sternotomies and are known to be high-risk candidates for heart transplantation. Beyond these excellent results in a difficult patient population, they have elucidated an interesting finding regarding PVR in the patients. They found that cardiac transplantation unmasked pulmonary vascular disease not evident at pretransplantation assessment.

I have three questions, Dr Mitchell. My first question relates to the decision process for the patient with failing Fontan circulation and atrial arrhythmias. I noticed in your series that at least 4 of the patients with late Fontan circulation failure had atrial flutter as part of their transplantation indications. We now have 60 patients at Children's Memorial Hospital who have undergone Fontan conversion with arrhythmia surgery. In that series, 7 patients were actually initially referred for heart transplantation. In our 60 Fontan conversions, we've had an operative mortality of $2 \%$, and 4 patients have required late cardiac transplantation between 8 days and 33 months after the conversion operation. When should we recommend cardiac transplantation, and when should we recommend Fontan conversion with arrhythmia surgery?

My second question relates to your uncovering of the underestimation of PVR before transplantation. What criteria would you use for declaring a patient not a candidate for cardiac transplantation on the basis of PVR in the presence of a functioning Fontan circulation?

My final question relates to the etiology of the elevated PVR. Some groups believe that the administration of warfarin decreases the incidence of chronic microemboli through the years, which might contribute to keeping the PVR low. What role do you think the administration of warfarin has for the patient with a Fontan circulation? Were your patients treated with warfarin, and what do you think about this particular theory in light of your interesting data?

Dr Mitchell. First, I would say that transplantation is a last resort for these patients, and patients that are deemed to be good candidates for conversion with or without arrhythmia surgery should undergo that as opposed to transplantation. Having said that, in our series there were 4 patients with atrial flutter; 3 of those
4 also had PLE, and the other patient already had a previous conversion to an extracardiac conduit. So I think that few if any of those patients would have been good candidates to go on to another conversion procedure.

I would say that the information from your group-which is remarkable, the results have been just spectacular in terms of mortality in particular-is something that we've taken to heart during the last several years. Most of these patients actually had their transplants well before your results were published, so we have begun to look much more strongly at that option for several patients we've seen recently. Having said that, I'm not certain that from our data we can tell you when you should transplant and when you should do a conversion. I suspect that you probably have far greater experience in terms of how to determine when the ventricular function will respond to an atrial conversion or to correction of atrial arrhythmias. So when do we transplant? One of the problems with these patients is that they tend to percolate along fairly stably and then have a relatively rapid demise. So I think that waiting too long will increase the mortality. An early approach is probably favorable, and that's certainly something that we have tried to do. We try to make a decision early on in their process as to whether to go toward transplantation or try to nurse them along.

You asked what the criteria should be in terms of PVR in these patients. And I think that probably one of the more surprising findings for us is that the TPGs were really depressed at the pretransplantation evaluation. We have typically used a TPG of 20 $\mathrm{mm} \mathrm{Hg}$ as the absolute maximum, which is a bit higher; some groups have said to use $15 \mathrm{~mm} \mathrm{Hg}$. I think that in this population it should probably be lower, because we have certainly seen a marked increase in the real TPG after surgery.

Finally, you asked about warfarin as a treatment for these patients I think is probably warranted. Microemboli certainly may underlie some of the increased PVR if this is a real phenomenon, although there are a number of other possible reasons that the Fontan circulation itself might increase PVR. I don't think warfarin in and of itself is the only answer.

Dr John A. Hawkins (Salt Lake City, Utah). These are great results in a very difficult group of patients. My question has to do with a phenomenon that I believe very few of us in this room can directly experience, and that is the Fontan procedure at high altitude. How much of your findings do you think may be due to the fact that these were patients who underwent a Fontan procedure and subsequently remained at high altitude for some time? How might that have affected your PVR or TPG? Would you obtain these same findings in a patient with a Fontan procedure at low altitude or at sea level?

Dr Mitchell. I can only speculate on that. For one thing, about $40 \%$ of these patients were referred from elsewhere, so their Fontan procedures and much of their palliative life had not been spent at the altitude at which we live. On the other hand, if you extrapolate what is known from normal patients to this population, it certainly is cause for concern. For example, the normal mean PAP measured at sea level, and most of this is from work done in the $1960 \mathrm{~s}$, is roughly 12 to $13 \mathrm{~mm} \mathrm{Hg}$, whereas people at the University of Colorado determined in the 1960s that mean PAP in Denver is about $16 \mathrm{~mm} \mathrm{Hg}$. So there is a small incremental increase in that 5000 feet of increased elevation. But if you take patients at 10,000 feet, such as in Leadville, Colo, the mean PAP 
is $24 \mathrm{~mm} \mathrm{Hg}$. So there is an increase above the altitude that Salt Lake City lies at and a more substantial increase above Denver, so that there is probably a greater impact on the patients that truly live in the mountains versus the patients at the more moderate levels at which we live. Beyond that, I really think this is an area for investigation in which we are certainly interested.

Dr Gil Wernovsky (Philadelphia, $P a$ ). This was a terrific presentation. First, I have a similar question in terms of where the patients lived and for how long. Did you have those data before and then after transplantation?

Second, do you have any similar data on, say, patients with cardiomyopathy? Is there something unique about the transplant itself that changes TPG or PVR in patients who may have started with a biventricular circulation?

Dr Mitchell. Taking your second question first, we have not looked at that yet in patients with cardiomyopathy. I considered trying to do that as a control group, but I think that chronic elevation of left atrial pressure itself can induce pulmonary vascular disease. Therefore, patients with cardiomyopathy who have much worse ventricular function than these patients are probably not an appropriate control group, which is why we looked at normal values versus the abnormal.

Please remind me of your first question.

Dr Wernovsky. I was wondering if you had any of the demographic data on the patients, and would you recommend that they can now move back to Denver, whereas they might have been living down at sea level because of their Fontan state?

Dr Mitchell. I don't have that information. I can tell you that $40 \%$ were treated previously and either moved to Denver or were directly referred to Denver for transplantation. In a series this small, I'm not sure what we could really learn, except to tell you that there is a strong bias among the cardiologists in our region to encourage these patients to live at sea level if at all possible.

Dr Wernovsky. Were the pretransplantation evaluations done in Denver, or were the catheterization data from other institutions?

Dr Mitchell. With the exception of I think 2 patients, all evaluations were done in our institution. One evaluation was done outside the area and 1 was done in another institution in Denver.

Dr Francois Lacour-Gayet (Denver, Colo). I take the freedom to discuss this paper from Denver, as I have nothing to do with this wonderful result. As I have discussed before, I think this is probably the first article to prove, attempt to prove, or even suspect that the mode of failure of the Fontan circulation in the long term can be elevation of PVR. It could be that living at a high altitude can increase this phenomenon.

I know how long you spend on your data. Please give us your feeling about this interesting proof that came out from your study.

Dr Mitchell. I hesitate to say that we proved that the Fontan creates an increase in PVR, and I think that we're very limited in our ability to do so. I've looked at the prepalliation data that we were able to obtain, which unfortunately is in quite a minority of cases, but I can tell you that the prepalliation mean PAP in the patients for whom we had data was $5 \mathrm{~mm} \mathrm{Hg}$ lower than their pretransplantation data. That, in combination with the length of palliation these patients had and their finding that the only those with normal PVR had early failure, is suggestive that the Fontan circulation itself may increase PVR, but it is clearly not proof.
The second thing that I would say is that we had enough difficulty relying on the pretransplantation assessments, and it is even more difficult to calculate an accurate PVR in a patient before palliation because of so many of the anatomic and multiple sources of collateral flow that are often present in those patients.

Dr Michal Wojtalik (Poznan, Poland). Fontan pulmonary circulation is an area of nonpulsatile flow lasting for a very long time, and introduction of pulsatile flow might cause a kind of limitation of the vasculature. Do you think that this is why the PVR rises?

Dr Mitchell. I think exactly the opposite, and it is not my thinking, it is from writing from authorities in this field. The coupling of the right ventricle to the pulmonary artery and the energy imparted into the pulmonary vasculature by a pulsatile system is necessary to keep the distal pulmonary tree open. Having had the absence of that for their entire lives and then having the introduction of pulsatile energetic flow into the pulmonary arteries, it doesn't seem that that process was reversed in these patients, which is what I would have expected. I think that there is some fixed element of disease that's brought out by the increased energy and the increased cardiac output in those patients.

Dr Thomas L. Spray (Philadelphia, Pa). You have really hit on the fundamental question here. Is this resistance fixed, or is it going to change with time? If it is a reintroduction of pulsatile flow and you can remodel the distal vasculature, then theoretically, the PVR should potentially decrease with time. If it's related to thromboembolism, presumably it is fixed and will not remodel.

Did you do any kind of manipulations in the catheterization laboratory to look and see whether there was any reactivity to this PVR in the posttransplantation period, and did you follow up the patients sequentially during the posttransplantation interval to see whether there was any change in their PVR?

Dr Mitchell. We did not look at reactivity, primarily because when these studies were done it wasn't even a consideration. The studies were done as part of posttransplantation surveillance, primarily looking for rejection. Looking at the patients who've undergone serial examinations, if anything, what we've seen in many of them is a progressive increase in PVR. There were very few in whom it had fallen. What I have noted is that patients who have had problems with rejection or who have had significant CAD and have late-failing Fontan circulations tend to be the ones with the increasing PVR. As far as how much of this is fixed, we have no data to really be able to comment on that. When I say "fixed," I just mean the simple introduction of increased flow manifests an increased TPG without any attempt at pulmonary vasodilation or anything to really assess for what we would traditionally be talking about in reactivity.

Dr W. Steves Ring (Dallas, Tex). One of the other things you might consider is the role of the immunosuppressant agents, particularly the calcineurin inhibitors such as cyclosporine (INN: ciclosporin), which are known to cause increased systemic vascular resistance and also have some minor, lesser effects on PVR. This could explain a lot of the changes that you've seen, irrespective of the Fontan physiology.

Dr Mitchell. I think that's a good point. I wasn't aware of their direct effect on the vasculature. There is simply no way I think we can separate out the influence of transplantation versus the influence of the previous disease process, except to say that I attempted 
to look at pathologic processes in the few patients who eventually died. Among those patients, we were able to come up with tissue in 1 case, and that patient did have medial muscular hypertrophy

I don't know what the mechanism behind calcineurin inhibitors is, and we certainly don't know what the mecha- nisms are behind the changes in patients with Fontan circulation, but we are not talking about large magnitudes of pulmonary vascular disease. The point is, in this patient population, it doesn't take a lot, most likely, to create problems; whereas in a normal biventricular circulation, this level of disease is well tolerated.

\section{ON THE MOVE?}

Don't miss a single issue of the journal! To ensure prompt service when you change your address, please photocopy and complete the form below.

Please send your change of address notification at least six weeks before your move to ensure continued service. We regret we cannot guarantee replacement of issues missed due to late notification.

\section{JOURNAL TITLE:}

Fill in the title of the journal here.

\section{OLD ADDRESS:}

Affix the address label from a recent issue of the journal here.

\section{NEW ADDRESS:}

Clearly print your new address here.

Name

Address

City/State/ZIP
COPY AND MAIL THIS FORM TO:

Elsevier Inc.

Subscription Customer Service

6277 Sea Harbor Dr

Orlando, FL 32887
OR FAX TO:

407-363-9661

OR E-mail:

elspcs@elsevier.com
OR PHONE:

800-654-2452

Outside the U.S., call

407-345-4000 